\title{
Occurrence of depression in patients with psoriasis - the role of inflammation, stress and mechanism of the vicious circle
}

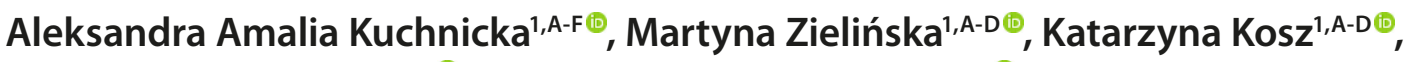 \\ Natalia Zarankiewicz ${ }^{1, A-D}{ }^{\oplus}$, Halina Piecewicz-Szczęsna ${ }^{1, E-F} \odot$ \\ 1 Department of Epidemiology and Clinical Research Methodology, Medical University, Lublin, Poland \\ A - Research concept and design, B - Collection and/or assembly of data, C - Data analysis and interpretation, \\ $D$ - Writing the article, $E$ - Critical revision of the article, $F$ - Final approval of article \\ Kuchcicka AA, Zielińska M, Kosz K, Zarankiewicz N, Piecewicz-Szczęsna H. Occurrence of depression in patients with psoriasis - the role of \\ inflammation, stress and mechanism of the vicious circle. J Pre-Clin Clin Res. 2020; 14(2): 58-61. doi: 10.26444/jpccr/122221
}

\begin{abstract}
Introduction. Psoriasis is a chronic skin disease which can have a detrimental impact on the patient's life. The correlation between depression, psoriasis and inflammation is a subject of many publications. The depressive and psoriatic symptoms, unhealthy coping strategies and stigmatization might be presented in the mechanism of the vicious circle. The appropriate understanding of this phenomenon might be extremely useful for specialists to improve their bedside manner.

Objective. The aim of this review is to analyze the current data about the worldwide presence of the major depressive disorder - psoriasis, and the occurrence of depression in patients suffering from psoriasis. Research and analysis were based on searching sources such as PubMed, UpToDate and World Health Organization pages for the integrative publications collected mainly from last 10 years. The data about the origin of the psoriasis disease was taken from as 1979 publication. State of knowledge. The study demonstrated that the link between psoriasis and depression is bi-directional. The proinflammatory cytokine, such as IL-6, TNF-a, CRP and IL-17, are elevated in both cases, which provokes the exacerbation of sickness symptoms. The inflammation dangerously disturbs the functioning of neuronal system and human homeostasis. Summary. According to the cited research, the prevalence of depressive disorders in psoriatic patients is higher in comparison to people without psoriasis. Inflammation plays an essential role by being a peculiar connector between psoriasis and depression. Stress and inflammation are crucial factors in pathogenesis of those two disorders and triggers the pathological mechanisms.
\end{abstract}

\section{Key words}

psoriasis, depression, inflammatory disease, skin disease, inflammation

\begin{abstract}
Abbreviations
3-HK - 3-hydroxykynurenine, BBB - Blood-Brain Barrier; CPRD - Clinical Practice Research Datalink; CRH - Corticotrophinreleasing Hormone; CRP - C-Reactive Protein; CSF - Cerebral Spinal Fluid; DLQI - Dermatology Life Quality Index; GAD-7 - Generalized Anxiety Disorder Scale; GR - The Glucocorticoid Receptor; HPA - Hypothalamic-Pituitary-Adrenal; ICD

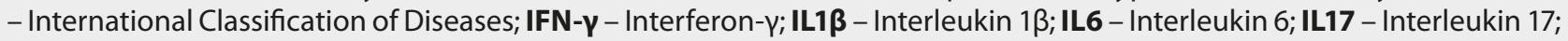
IL17A - Interleukin 17A; IL22 - Interleukin 22; MDD - Major Depressive Disorder; TNFa - Tumor Necrosis Factor-a; PASI Total Psoriasis Area Severity Index; PHQ-9 - Patient Health Questionnaire Depression Scale; PSS - Perceived Stress Scale; RR - Relative Risk; QA - Guinolinic Acid; WHO - Word Health Organization; YLDs - Years Lived with Disability; 5-HTT - The Serotonin Transporter
\end{abstract}

\section{INTRODUCTION}

Psoriasis is a long-lasting, relapsing, and one of the most common chronic, potentially multi-system diseases, which is marked by skin changes. The etiology seems to be unclear, although there is indisputable evidence that it is determined by genetic and inflammatory factors. The promising treatment of cyclosporine about forty years ago highlighted the fact that the immune system (T cells) plays a part in the pathogenesis of psoriasis [1]. From the pathological point of view, acute inflammatory neutrophils activate the cascade eventuate in macrophages, $\mathrm{T}$ cells and mediators, which secrete the chemokines and cytokines. Collaterally,

Address for correspondence: Aleksandra Amalia Kuchnicka, Department of Epidemiology and Clinical Research Methodology, Medical University, Lublin, Poland

E-mail: kuchnickaola@gmail.com

Received: 21.04.2020; accepted: 10.05.2020; first published: 02.06.2020 immune cell activity (myeloid and lymphoid) provokes proinflammatory cytokines, such as IL1 $\beta$, IL6 and TNF- $\alpha$, which along with T cell activation and release of notably: IL17A, IL22 and IFN- $\gamma$, leads to inflammatory effects in psoriasis $[2,3]$.

There are various factors, such as: physical trauma, psychological stress, drugs, infections or genetic susceptibility, which trigger and exacerbate the epidermal modification [4]. The level of several biomarkers, such as: fibrogen, resistin (adipose tissue-specific secretory factor), Complement 3, lipocalin-2, sE-selectin, is higher compared to healthy controls $[5,6]$. Genetic and epigenetic changes, alteration of the immune system, secretion of pro-inflammatory cytokines, hyperactivity of the epidermal keratinocytes, and consequently the hyperproliferation, cause the psoriatic phenotype [2]. This destructive process is responsible for the main symptoms (including erythematous). Psoriasis is characterised by itchy, painful and reddish patches such as papules, plaques or silvery scales. These changes do not scar the skin, however 
they may cause local haemorrhage when removed, which is called Auspitz sign [7]. The appearance of psoriasis can vary a great deal, from limited to widely spread skin lesions. It can develop on the entire body depending on the type of psoriasis. In this regard, $4.2-69 \%$ of patients have nail changes, whereas $1.3-34,7 \%$ of individuals suffer from chronic arthritis [8]. Affecting the joints and internal organs can lead to disability.

According to worldwide epidemiological data, the prevalence of psoriasis is estimated to be between $0.5-$ $11.4 \%$ in adults, and about $0-1.4 \%$ in children [9]. In compliance with a cohort study by Springate et al. using the UK CPRD between 1999 and 2013, a gradual increase of prevalence from $2.3 \%-2.8 \%$ was depicted [10]. J. M. Fernández-Armenteros et al., collected data from 398,701 individuals, $18.12 \%$ of whom were under 18 years of age [11]. A total of 6,556 people were diagnosed with psoriasis and 3,799 (55.31\%) were males. An unquestionable role is played by geographical location, in such a way that the rate of occurrence is increasing proportionally to the distance from the equator [9]. Around one million Polish, 7.4 million Americans and more than 125 million people worldwide arte affected by this disease [12]. Psoriasis is more common in adults than in children. Most patients are in the $30-39$ or $50-69$ age range; nonetheless, it may begin at any stage of life $[8,9]$. The quoted data clearly show that psoriasis might be regarded as a real global problem [8].

The mechanism of vicious cycle. The skin is the very complex outer tissue of the body. It is the largest organ of humans body, which provides protection, sensation or temperature regulation [13]. Furthermore, it is important to underline its psychosocial function: it plays an essential role in the interaction with the environment and helps people to communicate. Not surprisingly, the condition of the skin is a significant factor which determines feelings of attractiveness; therefore, any kind of skin changes might reflect on mental health.

As evidenced by studies, there is a frequent comorbidity of other systemic diseases which include: metabolic syndrome (including hypertension), cardiovascular diseases, inflammatory bowel disease, nicotinism, alcoholism, or psychiatric disorders $[8,14]$. This implies that psoriasis is highly associated with atherosclerosis and vascular inflammation, and that patients have increased levels of triglycerides and cholesterol [8]. Taking all those elements (skin changes and comorbidities) into account, psoriasis might result in the stigmatization of the patient, significant reduction in the quality of life and productivity at work or school. Insidiously, step by step, it leads to deterioration of mood, lower selfesteem, feelings of shame, and even distress. Those factors may cause sexual disorders, relationship problems and destroy social life $[14,15]$. Consequently, patients start to feel anxious (often paroxysmally), which can be connected with a high-level risk of development of depression. The Hospital Anxiety and Depression Scale, which is one of the major scales used in this case, proves that depression is decidedly higher in patients with psoriasis $[15,16,17]$. Patients who are dealing psoriasis and comorbidities (including depression) tend to have more harmful coping strategies, like drinking alcohol, smoking, having an unhealthy diet, or living a sedentary lifestyle. Emotional disorders and such bad habits cause passivity in their treatment. Demotivated patients neglect medical recommendations, which can have several consequences. It may lead to a reduction in the effectiveness of treatment and an increase in clinical symptoms of psoriasis in the mechanism of a dangerous vicious circle [15].

Depression. Clinical depression, also called major depressive disorder, is a severe mood condition, which takes control of patient's life. According to the WHO, more than $80 \%$ of people experience mental health disorders, which leads to more than US\$ 1 trillion economic looses per year [18]. The mental health conditions cause an early mortality of 10 20 years. There are various theories on the pathogenesis of the depression. To diagnose depression (according to the Diagnostic and Statistical Manual of Mental Disorders [DSM] and ICD), five or more conditions must be achieved: depressed mood/anhedonia, significant weigh loss/gain or changes with appetite, insomnia/hyperinsomnia, psychomotor agitation/ retardation, fatigue/loss of energy, feelings of worthlessness, indecisiveness/problems with thinking or concentrating, and repetitive thoughts about death/suicide. The prevalence of symptoms must last at least two weeks $[19,20]$. It touches every aspect of life, including the patient's family or social environment in general. The prevalence of depression has overwhelmingly increased with time $[20,21]$.

According to data, more than 264 million people worldwide suffer from clinical depression. In 2007, this affliction became the third leading cause of all-age YLDs, which is a measurement of the burden of the disease [22]. The WHO has prognosticated that by 2030 clinical depression will rank as the first leading cause of YLSs. According to the Substance Abuse and Mental Health Services Administration data from 2017, there are around 17.3 million people (aged 18 or older) in the United States who have had at least one clinical depressive episode - the equivalent of 7.1\% of all American adults [20].

Regarding the prevalence in Europe, the number of cases may also illustrate the seriousness of the situation: almost 84 million Europeans are affected by mental health problems. Every year, tens of millions of people have at least one mental health problem, and tens of thousands die through mental disorders, or from suicide [23]. Polish epidemiological data based on study in 2012, show that there are around 766 thousand people who have experienced a depressive episode during their lifetime. (these data do not include the population of children and people over 65-years-old) [24]. Clinical depression in particular affects over 21 million people (4.5\% of population) [23].

Despite the fact, that access to the medical information (publications, researches, open access data) is becoming more and more widespread, looking for help or mental health problems might be still regarded as embarrassing.

Questionable relationship between depression, inflammation and psoriasis. The link between psoriasis and depression can be explained by the common pathway of inflammation [25]. Studies have demonstrated that elevated baseline inflammation (including several pro-inflammatory substances: IL-6, TNF- $\alpha$, CRP, IL-17) in patients with depression, which also occur in psoriasis [3, 16, 20, 22, 29]. Those cytokines cause the psoriatic lesions by migrating towards the epidermis [3]. The brain tissue is protected by $\mathrm{BBB}$, which is responsible for maintaining the homeostasis and enable the correct state of brain functioning [22]. High level of cytokines interfere with the permeability of the BBB, and cross it in the process. The function of the neuroendocrine system, metabolism of the neurotransmitters (dopamine, 
serotonin), regulation of the main neurohormonal stress system - HPA axis, neural circuitry and plasticity of synapsis, are disrupted. [16, 27, 30]

The association between TNF- $\alpha$ and 5-HTT (in both basal physiological and pathological conditions) was confirmed in a study by Krishnadas's et al. [31]. At first, 13 neurologically healthy women took part in the investigation which proved that plasma TNF- $\alpha$ is correlated with 5-HTT availability. Furthermore, in 12 patients with psoriasis or PsA, the association was replicated. These results are connected with the serotonin hypothesis. The raphe nuclei (median and dorsal) localized close to the cerebral aqueduct in the mesencephala, constitute a part of $85 \%$ of serotonergic neurons in the brain. This localization make it particularly exposed to inflammatory molecules existing in CSF [32]. The 5-HTT regulates the synaptic serotonin levels and plays a crucial role in serotonin neurotransmission. Moreover, inflammation may cause a decline in the level of serotonin, the monoamine neurotransmitter, which is consider to be involved in appetite regulation, pain sensation and mood condition. This in turn, leads to the production of $3-\mathrm{HK}$, QA, which are neurotoxic serotonergic metabolites $[19,26]$.

Neuroinflammation and pro-inflammatory cytokines have close relationship with the hippocampal GRs and HPA axis [33]. Physiologically, the GR mediates the negative feedback of the HPA axis, which makes the ability of cortisol to inhibit its own secretion (especially as a defence against stress reaction). Contradistinctively, in depressive disorder, the impaired HPA axis negative feedback occurs as a result of the dysfunction of the GR. The interaction with other stress-inducted substances, damage-associated molecular patterns and inhibition on the receptors, causes hyperactivity of the HPA axis [34].

Stress seems to be a common and connective factor between psoriasis, depression, and finally inflammation. These variables interrelate and exacerbate each other [15]. While stress is activated (as a consequence of depressive mood), the sympathetic nervous system responds by releasing amines (e.g. norpinephrine) which stimulates the proliferation of myeloid cells. Additively, stress causes the up-regulation of $\mathrm{CRH}$, glucocorticoids and adrenocorticotrophic hormone with neuropeptide stress response mediators [35].

It might be considered that psoriasis has a one-sided impact on psychical disorders, whereas the cited examples show, in conclusion, that both conditions can affect and cause each other. In which case, psoriasis and depression involve more than the incidental comorbidities of each other [17].

Depression in psoriasis. In a study conducted by Lamb et al., 607 patients suffering from psoriasis completed the PHQ9, GAD-7 and DLQI questionnaires, which were a part of IMPARTS (Integrating Mental and Physical Healthcare) [36]. The vast majority of the patients were male $(65.2 \%)$, white British (69.5\%), with chronic plaque (95.7\%), and most of them had not been previously diagnosed with depression and anxiety (over 90\%). The results of this study showed that 60 patients (9.9\%) screened positive for probable MDD, of whom $42 \%$ reported severe symptoms. Moreover, 3.5\% indicated suicidal ideation. With regard to anxiety, $78 \%$ of the examined patients reached the threshold for clinical psychologist review, and $8,1 \%$ of patients qualified for both MDD and GAD.

A nationwide population-based cross-sectional study in Taiwan included 17,086 patients with psoriasis,to be and
$1,607,242$ patients from the general Asian population. The results showed that the prevalence of depression in patients with psoriasis was reported between $11.52 \%$, whereas in the general Asian population it was $7.73 \%$. Risk factors, which predispose psoriatic patients to depression, were: female gender, age 20-50 years, low income, or major comorbid disease (renal disease, cardiovascular disease, and cerebrovascular disease) [37].

Lakshmy et al., in across-sectional study on 90 patients in India suffering from psoriasis, with the majority of psoriasis vulgaris (75.6\%) [38], showed that 71 of the subjects (78.9\%) had major depressive disorder and 69 patients $(76,6 \%)$ had anxiety. Additionally, it was reported that 51 were dealing with significant stress and that 24 patients (16.6\%) assessed their quality of life from 'poor' to 'very poor'. PASI has been pointed to have a positive interrelation with such factors as depression, anxiety scores and PSS. A statistically high correlation was shown between severity of psoriasis (PASI) and PHQ-9, anxiety (GAD), and PSS. In conclusion, according to this study, the higher the PASI scores, the higher the grade of anxiety/depression.

Data collected by Dommasch et al. shows the risk of depression in women with psoriasis and psoriatic arthritis [39]. 50,750 American women took part in this cohort study, and the first results showed that the majority of women without psoriasis were more likely to be smokers, had higher prevalence of chronic conditions (such as cancer, diabetes, hypercholesterolaemia, rheumatoid arthritis) or higher BMI, compared with women suffering from psoriasis. The women without psoriasis were more likely to be psychically active. Secondarily, the age-adjusted RR of major depressive disorder was higher for women with psoriasis, compared with women without psoriasis. Further findings concentrated on PsA which evaluated that women without PsA had a lesser multivariate-adjusted RR of clinical depression than those with concomitant PsA.

The prevalence of depressive symptoms and clinical depression in patients with psoriasis was tested in a meta-analysis in 98 studies [40]. It was proven that psoriatic patients were at the very least 1.5 times more likely to suffer from depression, compared with patients without psoriasis. The majority of examined studies included those patients with plaque psoriasis which showed that the data was independent of gender distribution and mean age. Patients diagnosed with psoriatic arthritis, in contrast to studies by Dommash et al., did not show a higher prevalence rate of major depressive disorder [39].

Although the above research results show the scale of the phenomenon, knowledge about the connection between inflammation, depression and psoriasis should be ongoing. It is necessary to carry out further tests that will help with faster diagnosis, and more precise prognosis will improve the quality of the patient's life.

\section{CONCLUSIONS}

As evidenced by cited data, there is substantial evidence that there is an omni-directional correlation between inflammation, stress, depression and psoriasis.

Psychological factors have a crucial impact on the exacerbation and maintenance of the skin condition.

The role of psychological support and a multidisciplinary approach in psoriatic patients appears to be highly significant. 
The treatment of the psoriasis should be individual (including methods of reducing stress) along with the psychiatric assessment and appropriate pharmacotherapy.

\section{REFERENCES}

1. Mueller W, Herrmann B. Cyclosporin A for psoriasis. N Engl J Med. 1979 Sep; 301(10): 555. DOI: 10.1056/NEJM197909063011016

2. Alariny Ali Fouad, Farid Carmen Ibrahim, Elweshahi Heba Mahmoud, Abbood Sahar Salim, Psychological and Sexual Consequences of Psoriasis Vulgaris on Patients and Their Partners, The Journal of Sexual Medicine. DOI: https://doi.org/10.1016/j.jsxm.2019.08.017

3. Greb JE, Goldminz AM, Elder JT, Lebwohl MG, Gladman DD, Wu JJ, et al. Psoriasis Nat Rev Dis Primers, 2016; 2: 16082. DOI: 10.1038/ nrdp. 2016.82

4. Tara D Rachakonda, Clayton W Schupp, April W Armstrong, et al, Psoriasis prevalence among adults in the United States, Journal of the American Academy of Dermatology. 2014 March; 70(3): 512-516. DOI: https://doi.org/10.1016/j.jaad.2013.11.013

5. Bai F, Zheng W, Dong Y, Wang J, Garstka MA, Li R, An J, Ma H. Serum levels of adipokines and cytokines in psoriasis patients: a systematic review and meta-analysis. Oncotarget. 2017; 9: 1266-1278. https://doi. org/10.18632/oncotarget.22260

6. Blauvelt A, Ehst BD. Pathophysiology of plaque psoriasis, Uptodate Available from: https://www.uptodate.com/contents/pathophysiologyof-plaque-psoriasis (access: 2019.12.29)

7.Soutor C, Hordinsky MK. Clinical Dermatology 2013, Chapter 1, Pages 1-5. Available from: http://accessmedicine.mhmedical.com/content.as px?bookid=2184\$ionid=165458162. (access: 2019.12 .20 )

8. World Health Organization, Global Report on Psoriasis 2016

9. Feldman Steven R, MD, PhD, Epidemiology, clinical manifestations, and diagnosis of psoriasis, UptoDate. Available from: https://www.uptodate. $\mathrm{com} /$ contents/epidemiology-clinical-manifestations-and-diagnosis-ofpsoriasis\#H25 (access: 2019.12.30)

10. Springate D, Parisi R, Kontopantelis E, Reeves D, Griffiths C, Ashcroft D. Incidence, prevalence and mortality of patients with psoriasis: a U.K. population-based cohort study. Br J Dermatol. 2017; 176: 650-658. doi:10.1111/bjd.15021

11. Fernández-Armenteros JM, Gómez-Arbonés X, Buti-Solé M, BetriuBars A, Sanmartin-Novell V, Ortega-Bravo M, Martínez-Alonso M, Casanova-Seuma JM. Epidemiology of Psoriasis. A Population-Based Study. Actas Dermo-Sifiliográficas (English Edition). 2019; 110(5): 385-392. ISSN 1578-2190, https://doi.org/10.1016/j.adengl.2019.01.014

12. Borzęcki A, Koncewicz A, Raszewska-Famielec M, Dudra-Jastrzębska M. Epidemiology of psoriasis in the years 2008-2015 in Poland Przegląd Dermatologiczny. 2018 Jan; 105(6): 693-700. DOI: https:// doi.org/10.5114/dr.2018.80837

13. Patel N, Nadkarni A, Cardwell LA. et al. Am J Clin Dermatol (2017) 18 613. https://doi.org/10.1007/s40257-017-0279-8

14. Rigas HM, Bucur S, Ciurduc DM, Nita IE, Constantin MM. Psychological Stress and Depression in Psoriasis Patients - a Dermatologist's Perspective. Maedica (Buchar). 2019 Sep; 14(3): 287-291. doi: 10.26574/ maedica.2019.14.3.287

15. González-Parra S, Daudén E. Psoriasis and Depression: The Role of Inflammation. Actas Dermo-Sifiliográficas (English Edition). 2019; 110(1): 12-19. https://doi.org/10.1016/j.ad.2018.05.009

16. Martínez-Ortega JM, Nogueras P, Muñoz-Negro JE, Gutiérrez-Rojas L, González-Domenech P, Gurpegui M. Quality of life, anxiety and depressive symptoms in patients with psoriasis: A case-control study Journal of Psychosomatic Research. 2019 Sep; 124: 109780 https://doi. org/10.1016/j.jpsychores.2019.109780

17. Tohid H, Aleem D, Jackson C. Major Depression and Psoriasis: A Psychodermatological Phenomenon. Skin Pharmacol Physiol. 2016; 29: 220-230. https://doi.org/10.1159/000448122

18. World Health Organization (2019), The WHO Special Initiative for Mental Health (2019-2023): Universal Health Coverage for Mental Health, https://apps.who.int/iris/bitstream/handle/10665/310981/ WHO-MSD-19.1-eng.pdf?ua=1 (access: 2020.02.12)

19. Krishnan R, Roy-Byrne PP, Solomon D. Unipolar depression in adults: Epidemiology, pathogenesis, and neurobiology https:// www.uptodate.com/contents/unipolar-depression-in-adultsepidemiology-pathogenesis-and-neurobiology?search=depression $\% 20$ epidemiology\&source $=$ search_result\&selectedTitle $=1 \sim 150 \&$ usage type $=$ default $\&$ display_rank=1 (access: 2020.01 .31$)$

20. GBD 2017 Disease and Injury Incidence and Prevalence Collaborator Global, regional, and national incidence, prevalence, and years lived with disability for 354 diseases and injuries for 195 countries and territories, 1990-2017: a systematic analysis for the Global Burden of Disease Study 2017. The Lancet. 2018; 392(10159): 1789-1858. ISSN 0140-6736, https://doi.org/10.1016/S0140-6736(18)32279-7.(http:// www.sciencedirect.com/science/article/pii/S0140673618322797)

21. Malhi GS, Mann JJ. Depression. Lancet. 2018; 392(10161): 2299-2312. doi:10.1016/S0140-6736(18)31948-2

22. National Institution of Mental Health (NIH) https://www.nimh.nih. gov/health/statistics/major-depression.shtml\#part_155033 (access: 2020.01.31)

23. Moskalewicz J, Boguszewska L. Poprawa stanu zdrowia psychicznego Polaków. Diagnoza i rekomendacje. In: Szymborski J. Zdrowie publiczne i polityka ludnościowa. Warszawa. Rządowa Rada Ludności. 2012.

24. Hoseinzadeh, F, Abadi PH, Agheltar M, Aghayinejad A, Torabian F, Rezayat AA, Akbarzadeh F, Rahimi HR. The Role of Immune System in Depression Disorder. Health. 2016; 8: 1726-1743. http://dx.doi. org/10.4236/health.2016.815167

25. Krishnadas R, Nicol A, Sassarini J, et al. Circulating tumour necrosis factor is highly correlated with brainstem serotonin transporter availability in humans. Brain Behav Immun. 2016; 51: 29-38. doi:10.1016/j.bbi.2015.08.005

26. Haapakoski R, Mathieu J, Ebmeier KP, Alenius H, Kivimäki M. Cumulative meta-analysis of interleukins 6 and $1 \beta$, tumour necrosis factor $\alpha$ and $C$-reactive protein in patients with major depressive disorder. Brain, Behavior, and Immunity. 2015; 49: 206-215. ISSN 0889-1591, https://doi.org/10.1016/j.bbi.2015.06.001

27. Varatharaj A, Galea I. The blood-brain barrier in systemic inflammation. Brain, Behavior, and Immunity. 2017; 60: 1-12. ISSN 0889-1591, https:// doi.org/10.1016/j.bbi.2016.03.010

28. Strawbridge R, Arnone D, Danese A, Papadopoulos A, Herane Vives A, Cleare AJ. Inflammation and clinical response to treatment in depression: A meta-analysis. European Neuropsychopharmacology. 2015; 25(10): 1532-1543. ISSN 0924-977X, https://doi.org/10.1016/j. euroneuro.2015.06.007

29. OECD/EU (2018), Health at a Glance: Europe 2018: State of Health in the EU Cycle, OECD Publishing, Paris. https://doi.org/10.1787/ health_glance_eur-2018-en

30. Stuart MJ, Singhal G, Baune BT. Systematic review of the neurobiological relevance of chemokines to psychiatric disorders. Front Cell Neurosci 2015; 9: 357. https://doi.org/10.3389/fncel.2015.00357

31. Krishnadas R, Nicol A, Sassarini J, Puri N, Burden AD, Leman J, Combet E, Pimlott S, Hadley D, McInnes IB, Cavanagh J. Circulating tumour necrosis factor is highly correlated with brainstem serotonin transporter availability in humans. Brain, Behavior, and Immunity. 2016; 51: 29-38. ISSN 0889-1591, https://doi.org/10.1016/j.bbi.2015.08.005

32. Alexis R Howerton, Alison V Roland, Tracy L Dorsal. Raphe Neuroinflammation Promotes Dramatic Behavioral Stress Dysregulation Bale Journal of Neuroscience. 2014 May; 34(21): 7113-7123. DOI: 10.1523/ JNEUROSCI.0118-14.2014

33. Yong-Ku Kim, Kyoung-Sae Na, Aye-Mu Myint, Brian E Leonard. The role of pro-inflammatory cytokines in neuroinflammation, neurogenesis and the neuroendocrine system in major depression. Progress in NeuroPsychopharmacology and Biological Psychiatry. 2016; 64: 277-284. ISSN 0278-5846, https://doi.org/10.1016/j.pnpbp.2015.06.008

34. Carmine M. Pariante, Why are depressed patients inflamed? A reflection on 20 years of research on depression, glucocorticoid resistance and inflammation. European Neuropsychopharmacology. 2017; 27(6): 554 559, ISSN 0924-977X, https://doi.org/10.1016/j.euroneuro.2017.04.001

35. Moon HS, Mizara A, McBride SR. Dermatol Ther (Heidelb). 2013; 3 : 117. https://doi.org/10.1007/s13555-013-0031-0

36. Lamb RC, Matcham F, Turner MA, et al. Screening for anxiety and depression in people with psoriasis: a cross-sectional study in a tertiary referral setting. Br J Dermatol. 2017; 176(4): 1028-1034. doi:10.1111/ bjd. 14833

37. Hu SC, Chen GS, Tu HP. Epidemiology of Depression in Patients with Psoriasis: A Nationwide Population-based Cross-sectional Study. Acta Derm Venereol. 2019; 99(6): 530-538. doi:10.2340/00015555-3145

38. Lakshmy S, Balasundaram S, Sarkar S, Audhya M, Subramaniam E. A Cross-sectional Study of Prevalence and Implications of Depression and Anxiety in Psoriasis. Indian J Psychol Med. 2015; 37(4): 434-440. doi:10.4103/0253-7176.168587

39. Dommasch E, Li T, Okereke O, Li Y, Qureshi A, Cho E. Risk of depression in women with psoriasis: a cohort study. Br J Dermatol. 2015; 173: 975-980. doi:10.1111/bjd.14032

40. Dowlatshahi EA, Wakkee M, Arends LR, Nijsten T. The prevalence and odds of depressive symptoms and clinical depression in psoriasis patients: a systematic review and meta-analysis. J Invest Dermatol. 2014; 134: 1542-51. https://doi.org/10.1038/jid.2013.508 